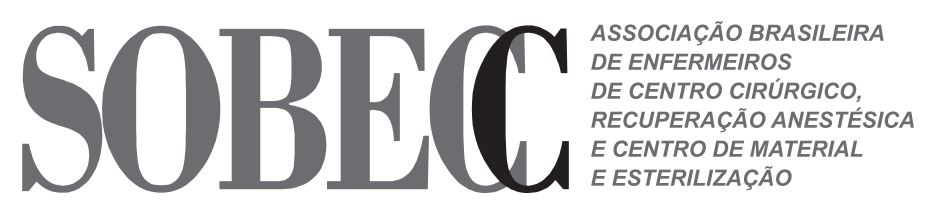

NACIONAL

\title{
A enfermagem e suas perspectivas
}

No ano do centenário do início da Primeira Guerra Mundial (considerado em 28 de julho de 1914), é oportuno lembrar a contribuição da enfermagem para a minimização dos impactos em saúde dos combatentes e das populações. A enfermagem teve um importante papel, tanto nos hospitais como nos campos de batalha. $\mathrm{O}$ trabalho desenvolvido pela enfermagem naquele período foi bastante árduo e perigoso, entretanto a contribuição desses profissionais não é completamente reconhecida atualmente.

Muitos foram os desafios que tiveram de ser enfrentados pelos enfermeiros em tempos de guerra. Devido à evolução dos armamentos de guerra, esses profissionais depararam-se com novas situações de trauma representadas por ferimentos à bala por metralhadoras, que produziam lesões com características diferentes das conhecidas até então; além disto, não raro contaminadas com a sujeira proveniente das trincheiras. Nessa progressão bélica, o ataque de gases passou a ser um risco não somente para os combatentes, como também para os profissionais de saúde, que precisavam atender nos acampamentos munidos de máscaras antigases. Nesse cenário terrível ainda somavam-se a inexistência de antibióticos, a disponibilidade de desinfetantes e antissépticos apenas rudimentares e os suprimentos limitados para os cuidados aos feridos. Não obstante as dificuldades, a enfermagem superou as limitações e gerou novos conhecimentos, oferecendo atendimento aos soldados e às populações.

Cem anos após, a enfermagem continua deparando-se com desafios continuados. Não se pode dizer que os tempos de guerra ficaram completamente no passado, dado o contexto mundial, longe de poder ser definido como de paz. Mais além, alterações demográficas, migração internacional, doenças emergentes, avanços no conhecimento e na tecnologia, aumento da necessidade de especialização, maior capacidade de informação do usuário dos serviços de saúde, pressão por privativação, proliferação de diferentes categorias profissionais nas equipes de trabalho e evolução do direito do trabalho e do mercado estão entre as situações que vão se acumulando, sem trégua, em uma dinâmica veloz que tem sido a característica da assistência à saúde no mundo contemporâneo.

Estão os enfermeiros preparados para as mudanças nos contextos sociais e do trabalho? Consumidos pela rotina e pela carga de trabalho, alguns profissionais podem não atentar para as necessidades que surgem em decorrência dessa dinamicidade, a qual se converteu em um fenômeno universal.

Em pouco tempo, a formação mais avançada na enfermagem deixará de ser opcional para ser um requisito mínimo de mercado. Ou seja, não bastará apenas ter a graduação em nível superior, os sistemas de saúde irão requerer profissionais cujas competências sejam complementadas por cursos de pós-graduação. 
A segurança do paciente, com foco na prevenção das Infecções Relacionadas a Assistência a Saúde (IRAS), será cada vez mais um componente básico para o desempenho da profissão, seja qual for a área de atuação do profissional.

Em consequência das pressões econômicas, a enfermagem deverá encontrar soluções criativas para a redução de custos e maximização da eficiência, adotando a medida necessária de flexibilidade que permita o alcance desses objetivos.

As instituições deverão preocupar-se com estratégias para a retenção de quadros qualificados para fazer face ao déficit de enfermagem, fenômeno que já está assolando nações desenvolvidas, como por exemplo Reino Unido e Estados Unidos da América. Com relação a esse último, estimase que em 2020 o déficit de enfermagem poderá chegar a aproximadamente 800 mil profissionais. Visando minimizar essa previsão, o governo americano destinou em 200220 milhões de doláres, no chamado nurse reinvestment act, para bolsas de estudo, programas de empréstimo educativo, campanhas para promover a profisssão e projetos para melhorar a comunicação e a percepção da sociedade com relação à profissão de enfermagem.

No Reino Unido, a publicação do Relatório Francis (2010), referente ao inquérito público realizado no hospital Stafford, demonstrou que a prática da instituição de redução do contingente de enfermagem visando a redução de custos acarretou sérios problemas na qualidade da assistência hospitalar. Em decorrência dessa publicação, a House of Commons, em Londres (2013), recomendou que as instituições devam assegurar número de profissionais suficientes para o cuidado apropriado dos pacientes. Entretanto, reconhece também que não basta a quantidade suficiente de trabalhadores, é preciso possuir a liderança apropriada para obter efetividade a partir da força de trabalho de que se dispõe.

Buscando alcançar as exigências e necessidades de saúde em perspectiva, o Institute of Medicine (IOM) publicou em 2011 um documento de chamada ao futuro da enfermagem, estimulando a categoria profissional a liderar as mudanças necessárias para o avanço equitativo dos sistemas de saúde. A enfermagem deverá manter o compromisso firme com a centralidade no paciente, visando um cuidado seguro e de alta qualidade.

Para atingir esse patamar, o enfermeiro do futuro deverá incorporar que ele é o responsável pela sua própria evolução e estruturar esse progresso. Os pilares desse processo são: a autogestão do conhecimento, na qual o indivíduo torna-se um agente ativo da sua capacitação e atualização; a incorporação da pesquisa como ferramenta para a qualificação do cuidado de enfermagem, adquirindo competência para o consumo racional da ciência produzida e para a geração de novos conhecimentos; a evolução contínua de suas habilidades sociais, com ênfase na participação no processo de engajamento do paciente e na constituição de equipes de trabalho com outros profissionais de saúde, para obtenção de um cuidado eficiente; e, for fim, o estabelecimento de um pensamento crítico e aberto que permita ao profissional reconhecer quais são as mudanças requeridas e liderá-las.

O futuro da enfermagem não deve ser algo que simplesmente acontece, mas sim consequência de planejamento e deliberação, visando a progressão da categoria. Para isso é preciso vigor e compromisso, seja em tempos de guerra, seja em tempos de "paz".

Maria Clara Padoveze

Professora Doutora do Departamento de Enfermagem em Saúde Coletiva, Escola de Enfermagem da Universidade de São Paulo. 


\section{Bibliografia consultada}

Calkin S. 10 frequently asked questions: what is the Francis Report? Nursing Times; jan. 2013. [cited 2014 Sept 11]. Available from: http://www. nursingtimes.net/home/francis-report/10-frequently-asked-questions-what-is-the-francis-report/5054230.article

Hendren R. Top 5 challenges facing nursing in 2012. HealthLeaders Media; nov. 2011. [cited 2014 Sept 11]. Available from: http://www. healthleadersmedia.com/print/NRS-273338

Institute of Medicine. The future of nursing: leading change, advancing health. Washington: The National Academies Press; 2011 [cited 2014 Sept 11]. Available from: http://www.nap.edu/catalog/12956.html

Kingma M. Nurses on the move: historical perspective and current issues. Online J Issues Nurs. 2008;13(2).

Püschel VAA, Ide CAC. As mudanças na enfermagem: a representação de enfermeiras acerca das mobilizações institucionais. Rev Esc Enferm USP. 2002;36(2):164-9. http://dx.doi.org/10.1590/S0080-62342002000200009

Trossman S. Caring knows no gender. Am J Nurs. 2003;103(5):65-8. http://dx.doi.org/10.1097/00000446-200305000-00024

United Kingdom. House of Commons. Health Committee. After Francis: making a difference. Third Report of Session 2013-14. London: The Stationery Office Limited; 2013 [cited 2014 Sept 11]. Available from: http://www.publications.parliament.uk/pa/cm201314/cmselect/ cmhealth/657/657.pdf 
